\title{
FUNGOS NA BIORREMEDIAÇÃO DE ÁREAS DEGRADADAS
}

\section{I.A. Soares ${ }^{1}$, A.C. Flores ${ }^{2 *}$, M.M. Mendonça ${ }^{3 * *}$, R.P. Barcelos ${ }^{4}$, S. Baroni ${ }^{5}$}

${ }^{1}$ Universidade Federal do Recôncavo da Bahia, Centro de Ciências da Saúde, Rua do Cajueiro s/nº, CEP 44574-490, Santo Antônio de Jesus, BA, Brasil. E-mail: belcbio@gmail.com

\section{RESUMO}

\begin{abstract}
O aumento das atividades industriais tem intensificado a poluição ambiental, promovendo a disposição inadequada de resíduos domésticos e industriais, principalmente resíduos perniciosos, implicando na contaminação do solo, ar, recursos hídricos superficiais e subterrâneos. Dentre as tecnologias mais utilizadas na recuperação dessas áreas degradadas, destaca-se a biorremediação, que tem, como agentes recuperadores, os micro-organismos. Portanto, o presente trabalho de revisão tem por objetivo abordar os principais aspectos da biorremediação por fungos - micorremediação de solos contaminados baseados nas diversas pesquisas já publicadas e disponíveis nos principais bancos de dados, tais como SciELO, LILACS, HighWire e PubMed. Essa biotecnologia vem sendo utilizada há vários anos em outros países e, em certos casos, apresenta menor custo e maior eficiência na remoção dos contaminantes do que as técnicas físicas e químicas que são atualmente utilizadas em escala comercial no tratamento de diversos resíduos e na remediação de áreas degradadas. Diante disso, é necessário que sejam realizados mais estudos para compreender os mecanismos de biorremediação mediada por micro-organismos, como ferramenta biológica no combate a poluição.
\end{abstract}

PALAVRAS-CHAVE: Poluentes, áreas contaminadas, fungos, solos, biorremediação.

\section{ABSTRACT}

FUNGI IN THE BIOREMEDIATION OF DEGRADED AREAS. The increase in industrial activities has intensified environmental pollution, promoting the improper disposal of household and industrial waste, especially hazardous waste, resulting in contamination of soil, air, surface water and groundwater resources. One of the technologies used in the recovery of these degraded areas is bioremediation, which uses microorganisms as recovery agents. Therefore, this review aims to address the main aspects of bioremediation by fungi - mycoremediation of contaminated soil based on various previously published studies available in major databases such as SciELO, LILACS, HighWire, PubMed. This biotechnology has been used for years in other countries, and in some cases has lower cost and higher efficiency in removal of contaminants than the physical and chemical techniques that are currently used on a commercial scale in the treatment of various wastes and the remediation of degraded areas. It is therefore necessary to develop further studies to understand the mechanisms of bioremediation mediated by microorganisms, as a biological tool in fighting pollution.

KEY WORDS: Pollutants, contaminated areas, fungus, soils, bioremediation.

O intenso aumento da população mundial gera uma busca cada vez maior de alimentos, espaço e condições para sobrevivência, fazendo com que as ações antrópicas ao meio ambiente sejam, ao longo do tempo, cada vez maiores (Alves, 2006). A intervenção do homem na paisagem natural, sua intensa atividade por meio de construção de estradas e barragens, mineração e áreas agrícolas mal manejadas são, em sua maioria, devastadora, propiciando o surgimento de áreas degradadas. Aliado a isso, a ocorrência do aumento dessas áreas se dá pela falta de conhecimento e de leis mais rígidas que protejam o ambiente (BEZERRA et al., 2006).

${ }^{2}$ Universidade Estadual de Maringá, Maringá, PR, Brasil.

${ }^{3}$ Universidade do Estadual do Oeste do Paraná, Cascavel, PR, Brasil.

${ }^{4}$ Universidade Federal do Paraná, Palotina, PR, Brasil.

${ }^{5}$ Universidade Paranaense, Toledo, PR, Brasil.

*Mestranda em Biologia Comparada - Universidade Estadual de Maringá.

**Mestrando em Recursos Pesqueiros e Engenharia de Pesca - Universidade do Estadual do Oeste do Paraná. 
O procedimento para remediação e consequente recuperação dessas áreas é lento e está relacionado à capacidade de restabelecimento do solo, onde se recompõem as características químicas, físicas e biológicas a um nível mínimo, que permita o desenvolvimento de espécies vegetais e da atividade microbiana, tão importante para o estabelecimento e sucessão da macrobiota (MeNdes FILHO, 2010). Segundo Alves (2006), restaurar ecossistemas é o que se tem atribuído ao desafio de, por meio de interferências planejadas, reconstruir a estrutura e criar condições para que se restabeleçam os processos ecológicos naturais de cada ecossistema.

Dentre as inúmeras tecnologias para remediação, destaca-se a biorremediação, como uma opção para promover a destoxificação do local ou a remoção de elementos contaminantes do solo. A estratégia de biorremediação consiste na utilização de processo ou atividade biológica por meio de organismos vivos (micro-organismos e plantas), que possuam a capacidade de modificar ou decompor determinados poluentes, transformando, assim, contaminantes em substâncias inertes (JACQUES, 2010). Esta biotecnologia vem sendo utilizada há anos em vários países e, em certos casos, apresenta menor custo e maior eficiência na remoção doscontaminantes doqueas técnicasfísicasequímicas, sendo atualmente utilizada em escala comercial no tratamento de diversos resíduos e na remediação de áreas degradadas (BAMFORTH; SINGLETON, 2005).

O emprego dos fungos na remoção dos poluentes começou a ser estudado nos últimos trinta anos do século XX. Peralta-Zamora et al. (1998), na busca por estudos de degradação de poluentes por fungos, citaram os primeiros trabalhos relatados com o uso de Saccharomyces cerevisiae para remoção de lindano e dieldrin por Nobles (1975) seguido do trabalho de KHINDARIA et al. (1975) que estudaram a degradação de heptacloro por fungos do gênero Aspergillus. Mesmo assim, foi apenas nas últimas décadas que houve incremento nas pesquisas de biodegradação por fungos (RODRIGUES, 2007). SINGH (2006) em seu livro entitulado: "Mycoremediation: fungal bioremediation" salientou que, por serem exímios biodegradadores de uma vasta variedade de compostos, os fungos são organismos promissores, que estão gerandocada vez mais resultados positivos para a recuperação de áreas degradadas por meio do processo de biorremediação. O autor, portanto, defende a utilização de termos mais específicos a fungos, ou seja: micorremediação, micodegradação e micodeteriorização.

Diante disso, o presente trabalho de revisão, teve por objetivo abordar as vantagens e aspectos do uso de fungosnos processos debiorremediação (micorremediação) de solos contaminados, baseando-se nas diversas pesquisas já publicadas e disponíveis nos bancos de dados como: SciELO, LILACS, HighWire e PubMed.

\section{Degradação de compostos químicos persistentes no solo}

Os estudos referentes à degradação de poluentes por fungos basidiomicetos tiveram início em 1980 com linhagens de Phanerochaete chrysosporium. Desde então, vários autores evidenciaram a capacidade desse organismo em degradar, além da lignina, um amplo espectro de poluentes como DDT [1,1-bis (4clorofenol)-2,2,2-tricloetano], lindano (hexaclorociclohexano), hidrocarbonetos aromáticos policíclicos (PAH), dioxinas (CAMERON et al., 2000) e outros poluentes orgânicos clorados (ZouAri et al., 2002).

Com o reconhecimento científico da capacidade dos micro-organismos de degradar compostos orgânicos, esses organismos vêm sendo utilizados ao longo do tempoem processos de tratamento biológico de efluentes líquidos e de resíduos sólidos. Devido a essa habilidade, têm sido desenvolvidos processos biotecnológicos, dentre os quais se destacam a degradação de poluentes, lixiviação de minerais, desobstrução de poços de petróleo e recuperação de locais contaminados - solo, águas superficiais e subterrâneas. Tais micro-organismos podem ser encontrados no próprio ambiente impactado, sendo, na maioria das vezes, os responsáveis pelo desaparecimento dos contaminantes (Oliveira, 2005).

Para a escolha de um micro-organismo que poderá ser potencialmente utilizado na remediação de uma área contaminada, necessita-se determinar sua capacidade em degradar o contaminante alvo eo tempo necessário para que isso ocorra (GEERDINK et al., 1996). Na literatura científica, bactérias, leveduras e fungos filamentosos são citados como agentes transformadores eficazes, face à habilidade em degradar uma ampla diversidade de substâncias orgânicas, comumente encontradas nos efluentes gerados pelas refinarias e indústrias.

Considerando que o metabolismo dos hidrocarbonetos aromáticos policíclicos (HAPs) gera compostos epóxidos, com propriedades carcinogênicas e mutagênicas, têm sido relatados inúmeros casos de câncer no pulmão, intestino, fígado, pâncreas e na pele, devidoà presença desses compostos (CHAKRADEO et al., 1993). Esses compostos químicos são gerados naturalmente, e de forma contínua, pela combustão incompleta de substâncias orgânicas, como resíduos vegetais, madeira e matéria orgânica. Porém, a contaminação do solo é um típico efeito da atividade antropogênica, devido à produção industrial de corantes, fibras sintéticas, preservantes de madeira, produção de carvão vegetal, extração e gaseificação do carvão mineral, processos de extração, transporte, refino, transformação e utilização do petróleo e de seus derivados (BAMFORTH; SINGLETON, 2005).

É sabido que para a degradação dos HAPs há um grande número de enzimas envolvidas, sendo que 
a maioria dos micro-organismos do solo não possui a capacidade de degradar os HAPs, justificando a necessidade de se isolar e selecionar micro-organismos potencialmente degradadores, visando à sua utilização na biorremediação de solos contaminados (AleXANDER, 1999).SegundoSilvaetal. (2008), a maior parte do conhecimento sobre rotas metabólicas de degradação desses compostos encontra-se fundamentada em bactérias. No entanto, estudos têm mostrado que fungos atuam como decompositores de compostos aromáticos, assim como de compostos fenólicos. Desde a década de 1950, vêm sendo isoladas bactérias degradadoras desses compostos, pertencentes principalmenteaos gêneros $P$ seudomonas, Aeromonas, Beijerinckia, Flavobacterium, Nocardia, Corynebacterium, Sphingomonas, Mycobacterium, Stenotrophomonas, Paracoccus,Burkholderia,Microbacterium, Gordonia, entre outros (JACQUES et al., 2010; JACQUES et al., 2007) e vários fungos dos gêneros Cunnighamella, Phanerochaete, Fusarium, Candida, Penicillium, Pleorotus, Trametes, Aspergillus, Bjerkandera e Chrysosporium (JACQUES, 2010).

Já para solos contaminados com fenóis e benzeno, Hofrichter et al. (1993) selecionaram os gêneros Penicillium, Mucor e Alternaria provenientes do efluente industrial no leste da Alemanha. PiecKová; JESENSKÁ (1999) investigaram a presença dos gêneros Penicillium, Cladosporium, Fusarium, Aspergillus, Aureobasidium, Trichoderma e Alternaria nas cozinhas, banheiros e porões em residências na Bélgica. ZhDANOva etal. (2000) isolaram os gêneros Penicillium, Cladosporium, Fusarium, Aspergillus, Aureobasidium, Acremonium e Mucor, em locais com altos índices de radiação na Usina Nuclear de Chernobyl, alguns anos após um acidente nuclear.

A biorremediação de HAPs também pode ser limitada se as condições do solo não forem favoráveis à sobrevivência e à atividade dos micro-organismos degradadores. A umidade do solo é considerada por HAIDER (1999) um fator ambiental crítico, pois uma alta atividade microbiana facilmente ocorrerá se houver adequada disponibilidade de água aos micro-organismos. Além disso, o teor de água no solo tem relação inversa com a disponibilidade de oxigênio e, consequentemente, com a atividade dos micro-organismos aeróbios, que são os principais responsáveis pela degradação dos HAPs. A temperatura afeta a atividade metabólica, o consumo de substrato pelos micro-organismos e, por consequência, a biodegradação dos HAPs.

O composto poluente 2-metil-1,3,5-trinitrobenzeno, mais conhecido como Trinitrobenzeno (TNT) e popularmente lembrado como um dos principais explosivos, não é fácil de ser degradado, pois o metabolismo oxigenado de bactérias para compostos aromáticos não ocorre no TNT por causa de suas propriedades químicas, já que as formas parcialmente reduzidas de TNT reagem entre elas na presença de oxigênio para formar compostos mais mutágenos que o próprio TNT e que não são metabolizáveis por micro-organismos. Entretanto, os processos anaeróbicos têm vantagens por causa da ausência de oxigênio. Por isso, o uso de fungos para a biorremediação do TNT tem gerado interesse considerável (EsTEVES-NunEZ et al., 2001).

O petróleo consiste de uma mistura de substâncias, que diferem em solubilidade, volatilidade esusceptibilidade à degradação por micro-organismos. Embora os hidrocarbonetos aromáticos possam ser degradados, a taxa e/ou habilidade desse processo diminui na mesma proporção do aumento de anéis benzênicos, baixa disponibilidade de oxigênio, nutrientes, entre outros fatores (CRAPEZ, 2001).

No caso da gasolina, que tem hidrocarbonetos monoaromáticos, benzeno, tolueno, etilbenzeno e os três xilenos orto, meta e para, chamados compostos BTEX, comoconstituintes, têm maior solubilidadeem água e, portanto, são os contaminantes que primeiro irão atingir o lençol freático (CORSEUIL et al., 1996). Uma das principais preocupações no derramamento da gasolina, então, é a contaminação de aquíferos que sejam usados como fonte de abastecimento de água para consumo humano. Por ser muito pouco solúvel em água, a gasolina derramada, contendo mais de uma centena de componentes, inicialmente estará presente no subsolo como líquido de fase não aquosa (NAPL).

Entretanto, a gasolina comercializada no Brasil é bastante diferenciada de outros países, pois é misturada com $22 \%$ de etanol. Deste modo, as interações entre o etanol e os compostos BTEX podem causar um comportamento completamente diferente no deslocamento da pluma do que aquele observado em países que utilizam gasolina pura (SANTOS et al., 1996). Existem poucos estudos que relacionam o impacto da presença do etanol na biodegradação dos compostos BTEX. Em estudos com metanol e compostos BTEX, BARKER et al. (1992) concluíram que a maior persistência dos BTEX em presença do metanol era causada pela inibição da biodegradação pela alta concentração de metanol e também devidoà remoção de oxigênio pela biodegradação do metanol.

SiLva et al. (2007), selecionaram linhagens de fungos filamentosos resistentes às condições adversas e capazes de degradar compostos fenólicos a partir de águas residuárias de postos de gasolina. As espécies isoladas pelos autores foram: Aspergillus flavus, Cladosporium sp., Penicilium sp. e Phoma sp.

WeNZel et al. (2006) isolaram e caracterizaram um fungo filamentoso de peças anatômicas conservadas em formol. O fungo foi identificado como Paecilomyces javanicus e, quando testado em meio sólido com diferentes concentrações de fenol, diesel e gasolina, os resultados demonstram que a tolerância do $P$. 
javanicus é bastante elevada, corroborando com os resultados encontrados por CONCEIÇÃO et al. (2005), que isolou Paecilomyces sp. de efluentes de uma refinaria de petróleo. O gênero Paecilomyces já foi descrito associado a processos de biorremediação com sucesso na degradação de vários compostos tóxicos, em especial as espécies $P$.variotti e $P$. niveus (CHAillan et al., 2004), onde apresentou um potencial regular na biorremediação com eficiência de aproximadamente $7 \%$.

PAssos et al. (2009) isolaram de um solo, contaminado por hidrocarbonetos derivados de petróleo, na região da Cidade do Rio Grande, RS, Brasil, uma linhagem de Aspergillus sp. LEBM2 e avaliaram a taxa de biodegradação de fenol em concentrações crescentes. Com os resultados, puderam concluir que Aspergillus sp. LEBM2 tem alta tolerância ao fenol, podendo degradá-lo efetivamente até uma concentração de $989 \pm 15 \mathrm{mg} \mathrm{L}^{-1}$, podendo ser empregado em processos de bioaumentação.

Em condições práticas, MACEDO; BERBERT, (2002) submeteram linhagens de fungos a teste de degradação de óleo cru e verificaram que. A. versicolor apresentou a maior eficiência de biodegradação e de remoção de matéria orgânica. Os referidos pesquisadores também fizeram o comparativo entre as eficiências de biodegradação do fungo filamentoso $(10,8 \%)$ e do consórcio microbiano $(7,39 \%)$, constituído de bactéria filamentosa e levedura, concluindo-se que A.versicolor pode ser apontado como um degradador em potencial dos hidrocarbonetos contaminantes presentes no solo impactado.

SicILIANO etal. (2003) avaliaram o impacto da remediação microbiana na massa do solo e a capacidade da comunidade microbiana em degradar hidrocarbonetos no intuito de determinar se os tratamentos defitorremediação aumentam o potencial metabólico da comunidade microbiana do solo pela alteração de sua estrutura taxonômica. Foi verificado que o melhor sistema de remediação para a diminuição da concentração de hidrocarbonetos no solo foi obtido pelo aumento da população bacteriana contendo genes para o catabolismo de hidrocarbonetos na comunidade da rizosfera, demonstrando-se, assim, a importância do uso de micro-organismos na fitorremediação.

\section{Degradação de metais pesados no solo}

De acordo com Malavolta (1994), o conceito "metal pesado" é aplicado a um grupo heterogêneo de elementos, incluindo metais, semimetais e não metais que possuem número atômico maior do que 20 ou peso específico maior que $5 \mathrm{~g} \mathrm{~cm}^{-3}$. Os principais metais pesados presentes no solo e nos produtos utilizados na agricultura são $\mathrm{Co}, \mathrm{Cd}$, $\mathrm{Cr}, \mathrm{Cu}, \mathrm{Fe}, \mathrm{Hg}, \mathrm{Mn}, \mathrm{Ni}, \mathrm{Pb}$, Sn e $\mathrm{Zn}$ (ABreu et al.,
2002). Entre esses, deve-se ressaltar que alguns são essenciais às plantas $(\mathrm{Cu}, \mathrm{Fe}, \mathrm{Mn}, \mathrm{Mo}, \mathrm{Ni}$, e $\mathrm{Zn})$, bactérias fixadoras de nitrogênio (Co e Mo), animais ( $\mathrm{Co}, \mathrm{Cr}, \mathrm{Cu}, \mathrm{Fe}, \mathrm{Mn}, \mathrm{Mo}$, e $\mathrm{Zn}$ ) e micro-organismos (Co, $\mathrm{Cr}, \mathrm{Cu}, \mathrm{Mg}, \mathrm{Mn}, \mathrm{Ni}$, e $\mathrm{Zn}$ ).

A contaminação dos solos por metais pesados pode ter origem natural ou antropogênica, sendo esta a principal razão do aumento crescente dos metais pesados nos solos, provocando, distúrbios muitas vezes de difícil recuperação para o ambiente (ABREU et al., 2002). Alguns metais pesados como cobre não são biodegradáveis apresentando uma dinâmica no solo bastante complexa, alterada diretamente por fatores do meio, principalmente pela composição química, física e mineralógica do solo, pela quantidade de matéria orgânica, $\mathrm{pH}$ e capacidade de troca de cátions (CTC) (SODRÉ; LENZI, 2001).

Os metais podem estar disponíveis no solo na forma de elementos solúveis, como íons livres, sendo absorvidos pelas plantas e ou lixiviados pelos solos (Guilherme et al., 1995) Mecanismos de adsorção específica, troca iônica e precipitação retêm os metais pesados no solo. Ocorrem também na forma de elementos trocáveis, sendo adsorvidos por forças eletrostáticas em sítios carregados negativamente na matéria orgânica ou em minerais, podendo estar adsorvidos especificamente, ligados a materiais orgânicos insolúveis ou precipitados na forma de carbonatos e sulfatos, entre outros (Costa et al., 2004).

O termo biorremediação, no caso dos metais pesados, pode parecer inapropriado, já que nenhum processo pode degradar ou eliminar elementos inorgânicos, no entanto, em alguns casos sua imobilização mediada pelos micro-organismos pode ser a única forma praticável para proteger águas subterrâneas e a cadeia alimentar de uma contaminação (SPROCATI, 2006).

Para o metal pesado cobre, as bactérias e os fungos do solo apresentam mecanismos para o transporte dentro de suas células. Determinadas proteínas protegem o micro-organismo dos efeitos tóxicos do metal, ligando-o a enzimas específicas (TURPEINEN, 2003). Nas bactérias, pode ocorrer o transporte do metal através de gradiente quimiosmótico pela membrana citoplasmática, diminuindo seu potencial tóxico (NIES, 1999).

Os micro-organismos respondem de maneira diferenciada quando expostos ao solo contaminado com metais pesados. Silva et al. (2007), em resultados preliminares, observaram que fungos ectomicorrízicos tolerantes a cobre, quando colocados em meio com adição deles, apresentaram melhor desenvolvimento. Nos seus resultados, a linhagem Pisolitus tinctorius 24 foi a que mais se desenvolveu nesse meio, pois, conforme houve aumento da dose do cobre, maior foi seu crescimento vegetativo. Já Suillus 2.8, Suilus 128 e Scleroderma 124 apresentaram menor 
desenvolvimento na proporção que se aumentou as doses de cobre. Diante desses dados, sugere-se que esses fungos não são indicados para programas de biorremediação de solos contaminados por cobre.

Silva Junior; Pereira (2007) isolaram fungos de solos contaminados com metais pesados provenientes de uma indústria metalúrgica sugerindo que os fungos dos gêneros Aspergillus, Thielavia e Penicillium são resistentes a altas concentrações de nitrato de chumbo. Segundo CHEw et al. (2001), a razão pela qual esses fungos possuem maior tolerância ao nitrato de chumbo ainda é incerta. Entretanto, afirmam que alguns micro-organismos possuem adaptações fisiológicas podendo assim tolerar e até mesmo interferir na disponibilidade dos metais no solo.

Para o gênero Aspergillus nidulans, foi verificado que as linhagens selvagem e mutante respondem de maneira diferente quando repicados em meios sólidos adicionados com os metais pesados: sulfato de cobre, sulfato de zinco e sulfato ferroso. Todas as linhagens apresentaram crescimento vegetativo, esporulação e pigmentação dos conídios, mas a linhagem mutante respondeu melhor nos meios com maior quantidade destes metais (MENDONÇA et al., 2009).

Cooley et al. (1986) observaram que o metal pesado cádmio em dosagens maiores causou efeitos deletérios sobre o metabolismo celular e progressiva inibição da esporulação do fungo A. nidulans, indicando não ser o organismo próprio para o processo de biorremediação.

Como os fungos apresentam grande capacidade de adaptação à presença de metais pesados no solo, a biorremediação utilizando fungos torna-se muito promissora na recuperação de áreas degradadas com metal pesado (GAAD, 2000).

\section{Degradação de pesticidas no solo}

A história do uso do solo mostra que a substituição de mata e de campos nativos leva a uma profunda alteração do sistema ecológico equilibrado, para dar lugar a plantações e criações. Essa alteração nem sempre dá lugar a um novo sistema ecológico sustentável, seja de lavouras ou de pastagens. Com isso, solos utilizados intensamente e de forma inadequada são levados à degradação. No mundo há dois bilhões de hectares de solos degradados, segundo a ONU e 100 milhões estão no Brasil (EMBRAPA, 2006).

Áreas agrícolas degradadas originam-se também após o intenso uso de pesticidas como fungicidas, inseticidas e herbicidas, dos quais parte é absorvida pela plantação e parte deposita-se no solo onde permanece por muito tempo, podendo deixar o solo impróprio para a produção de novas culturas e até atingir regiões profundas como lençóis freáticos.
Os compostos organoclorados são substâncias químicas que têm meia-vida longa ou lenta taxa de desaparecimento no ambiente, elevada toxicidade e persistência, tanto no meio ambiente como nos organismos vivos. Isso é devido principalmente a sua estabilidade química e também às condições ambientais desfavoráveis aos processos de mineralização ambiental ou biológica (BRO-RASMUSSEN, 1996).

Dentre os resíduos industriais estão os compostos poluentes persistentes, muitos agrotóxicos como o hexaclorobenzeno (HCB) e o pentaclorofenol (PCP). Segundo Morales; PAzos (1998), fungos basidiomicetos apresentam habilidade de degradar PCP e produtos relacionados devido à inespecificidade do sistema enzimático desses organismos que envolve peroxidases (LiP, MnP) (TIEN; KIRK 1988; Zouari et al., 2002), além da peroxidase versátil (RoDRíGueZ et al., 2004) e fenoloxidases como lacases e tirosinases (UlLAH et al., 2000; MonTIEL et al., 2004; RodrigueZ et al., 2004).

Os problemas relacionados aos efeitos dos pesticidas sobre os processos do solo estão baseados no fato de que muitas reações envolvidas na ciclagem de nutrientes são mediadas por micro-organismos e na possibilidade destes compostos entrarem na cadeia alimentar afetando organismos superiores como o homem. Os agrotóxicos e seu transporte através do solo são as maiores fontes de contaminação da água subterrânea. Em revisão sobre o comportamento de metalaxil (Armetil $\left.{ }^{\circledR}\right)$, um fungicida muito utilizado, SUKUL; SPITELLER (2000) concluíram que este composto pode migrar para os horizontes mais profundos e alcançar a água subterrânea, especialmente em solos com baixo conteúdo de matéria orgânica.

Ouso defungos para monitorar contaminações de solos e águas vem sendo bastante estudado (HÖLKER et al., 1995; PEINTNER; MOSER, 1996), pois a capacidade de bioadsorção dos fungos aplica-se a metais pesados (Peintner; Moser, 1996), defensivos agrícolas (PaoletTi, 1999), corantes e compostos radioativos (HAselwandTER; BerReCK, 1988), entre outros.

Em meados da década de 80 já haviam sido apresentadas evidências de que o fungo Phanerochaete chrysosporium tinha a capacidade de mineralizar DDT, TCDD (2,3,7,8-tetraclorodibenzeno-p-dioxina), benzo (a) pireno, lindano (1,2,3,4,5,6-hexaclorociclohexano) e algumas bifenilas policloradas (PCBs), bem como o pentaclorofenol (Bumpus; Aust, 1987; Barr; Aust, 1994; KaWamoto; Shim, 2002; Krishna, 2005; TORTELLA et al., 2005).

Os basidiomicetos são amplamente utilizados em estudos de biorremediação de poluentes orgânicos persistentes (POPs), tais como pesticidas clorados (DDT), dioxinas (2,3,7,8-tetraclorodibenzeno-pdioxina), bifenilas policloradas, além de hidrocarbonetos aromáticos (benzo-a-pireno), penta- 
clorofenol e hexaclorobenzeno. Tais linhagens de fungos envolvidas na degradação destas moléculas incluem as espécies: Higrocybe sp., Lentinus crinitus, Peniophoracinerea sp., Phellinus gilvus, Pleurotus sajor-caju, Psilocybe castanella, Pycnoporus sanguineus e Trametes villosa (MATHeuset al., 2000; Gugliotta, 2001; MACHADO et al., 2005; VitAli et al., 2006; BALlAMinUt; Matheus, 2007).

Determinadas plantas podem, por meio do processo de fitorremediação, absorver os pesticidas do solo, ou também promover um processo chamado fitoestimulação, no qual há liberação de exsudatos e enzimas que incrementam as transformações bioquímicas e/ou a mineralização em virtude da atividade microbiana e de fungos micorrízicos na rizosfera (WILSON; TISDELL, 2001). Normalmente, o efeito rizosférico da interface solo-raiz, que se deve à exsudação de nutrientes da planta, tais como aminoácidos e polissacarídeos resultam na proliferação da comunidade microbiana nessa região. Por essa razão, a rizosfera pode ser um ótimo sítio de degradação de compostos orgânicos indesejáveis, graças à comunidade microbiana associada (fungose bactérias), que pode utilizar os contaminantes como fonte de carbono primária e nutriente.

Embora os agrotóxicos possam ter efeito negativo na população microbiana, estudos mostram que bactérias podem resistir e até mesmo proliferar na presença de agrotóxicos em elevadas concentrações, maiores inclusive que as taxas aplicadas no campo. Para esse tipo de estudo, a taxa de evolução de $\mathrm{CO}_{2}$ do solo tem sido utilizada como índice da atividade, assim como o tamanho da biomassa microbiana do solo e, ainda, o metabolismo do carbono lábil do solo (PIRES, 2005).

Isolamento e seleção de fungos, Aspergillus, Penicillium e Trichoderma de solos contaminados com atrazine + zimazine, um herbicida usado no controle de ervas daninhas, apresentaram uma alta capacidade de crescimento em meios atrazine, indicando a possibilidade da utilização desses fungos em estudos de biorremediação (Colla et al., 2008).

Silva (2007) isolou fungos de solo brasileiro contaminado com o herbicida 2,4-D e analisou o potencial de degradação por cromatografia líquida de alta eficiência, identificando Serratia marcescens e Penicillium sp. como degradadoras de 2,4-D representando um grande potencial em biorremediação.

BARNABÉ (2003), em testes laboratoriais estudando a ação descontaminante dos herbicidas Paraquat e Diquat pelo fungo P. ostreatus, verificou resistência dos fungos e a biodegradabilidade dos herbicidas e, das quatro linhagens de $P$. ostreatus testadas, apenas CCB004 e 021 se mostraram potencialmente capazes de sobreviver e resistir a esse ambiente rico em Paraquat e Diquat, respectivamente.
Alguns estudos têm demonstrado a grande habilidade dos micro-organismos em degradar o carbaril presente no solo (KUO; REGAN, 1992). Os organismos mais frequentemente identificados são bactérias (Pseudomonas phaseolicola, P. cepaphia e Rhodococcus sp.) e fungos filamentosos (Aspergillus niger, A. terreus, Fusarium solani e Gliocladium roseum).

Em estudos preliminares, ELLIS; ELLIS (1997) mostraram que F. oxysporum UMC-01 mostrou-se sensível aos herbicidas da classe das triazinas. Segundo GALVÃoet al. (2003), o fungo apresentou alterações na pigmentação ena velocidade decrescimento, quando colocado na presença de diferentes concentrações de herbicida. O seu uso como bioindicador foi considerado promissor para o monitoramento de solos e águas contaminados por herbicidas.

\section{Considerações finais}

Os estudos dos processos de biorremediação vêm sendo desenvolvidos visando uma série de benefícios para o meio ambiente. Vários são os poluentes e os mecanismos necessários para a recuperação de áreas degradadas, porém, os micro-organismos e plantas possuem maneiras específicas para remoção, imobilização ou transformação de poluentes específicos.

Uma maneira de implementar este processo é buscar e isolar novos micro-organismos potencialmente capazes de degradar poluentes. Sabe-se que, no planeta, há uma grande diversidade de microorganismos ainda não identificados e classificados, que vivem em ambientes extremos (extremófilos), apresentando grande plasticidade adaptativa. A busca por esses organismos é fundamental para abrir novas perspectivas com vistas aos processos de recuperação de ambientes.

$\mathrm{O}$ advento da biotecnologia, seleção de genes e introdução de novos genes em micro-organismos, pode ser uma estratégia eficaz nas etapas de isolamento, melhoramento e obtenção de cepas e linhagens biorremediadoras.

O empenho da ciência, porém, não trará sozinha a solução para reverter os danos no ambiente. $\mathrm{O}$ processo de biorremediação há que ser trabalhado em nível social e cultural, visto que essa é ainda uma alternativa muito nova para o contexto das empresas poluidoras e da sociedade como um todo.

Faz-se importante um trabalho informativo, educativo e de conscientização sobre as vantagens no uso de micro-organismos em diversos processos de recuperação de ambientes contaminados. Sabese que, popularmente, há uma forte associação de micro-organismo com doenças infecto-contagiosas e, para que haja uma mudança desse paradigma, é importante incutir esse novo modelo na sociedade, usando para isso estratégias de divulgação dos resultados obtidos no meio científico. 
Torna-se urgente uma busca por novas possibilidades nos processos de uso de micorremediação, tanto pelos pesquisadores como pelos empresários e autoridades governamentais.

Sabemos que nosso planeta nos oferece um rico potencial microbiano, basta investir na busca de novas espécies e fazer uso da biotecnologia para tal.

Diante disso faz-se necessário a realização de mais estudos e pesquisas para compreender os mecanismos de biorremediação mediada por microorganismos, como ferramenta biológica no combate à poluição.

\section{REFERÊNCIAS}

ABREU, C.; ABREU, M.F.; BERTON, R.S. Análise química de solo para metais pesados. In: ALVAREZ, V.V.H.; SCHAEFER, C.E.G.R.; BARROS, N.F.; MELLO, J.W.V.; COSTA, L.M. (Ed.). Tópicos em ciência do solo. Viçosa: Sociedade Brasileira de Ciência do solo, 2002. v.2 p.645-692.

ALEXANDER, M. Biodegradation and bioremediation. 2.ed. New York: Academic Press, 1999. 453p.

ALVES, M.C. Recuperação dos solos degradados pela agricultura. In: ENCONTRO NACIONAL SOBRE EDUCAÇÃO AMBIENTAL NA AGRICULTURA, 5., 2006, Campinas. Anais. Campinas: Instituto Agronômico, 2006. 1-CD-ROM.

ANDERSON, P.; DAVIDSON, C.M.; LITTLEJOHN, D.; URE, A.M.; SHAND, C.A.; CHESHIRE, M.V. Extraction of ergosterol from peaty soils and determination by high performance liquid chromatography. Talanta, v.41, n.5, p.711-720, 1994.

BALLAMINUT, N.; MATHEUS, D.R. Characterization of fungal inoculum used in soil remediation. Brazilian Journal of Microbiology, v.38, n.2, p.248-252, 2007.

BAMFORTH, S.; SINGLETON, I. Bioremediation of polycyclic aromatic hydrocarbons: current knowledge and future directions. Journal of Chemical Technology and Biotechnology, v.80, n.7, p.723-736, 2005.

BARKER, J.F.; HUBBARD, C.E.; LEMON, L.A.; VOORO, K.A. The influence of Methanol in Gasoline Fuels on the Formation of Dissolved Plumes, and the Fate and Natural Remediation of Methanol and BTEX Dissolved in Groundwater. In: CALABRESE, E.J.; KOSTECKI, P.T. (Ed). Hydrocarbon contaminated soils and groundwater. New York: Lewis Publishers, 1992. p.558.

BARNABÉ, A.S. Processos de biodegradação dos herbicidas paraquat e diquat por fungos Basideomicetos. Uma proposta para a biorremediação de solos. 2003. 74p. (Dissertação de Mestrado) - Universidade de São Paulo, Faculdade de Saúde Pública, São Paulo, 2003.
BARR, D.P.; AUST, S.D. Mechanisms white rot fungi use to degrade polluants. Environmental Scince and Technology, v. 28, p. 78-87, 1994.

BEZERRA, F.B.; OLIVEIRA, M.A.C.L.; PEREZ, D.V.; ANDRADE, A.G. de; MENEGUELLI, N.A. Lodo de esgoto em revegetação de área degradada. Pesquisa Agropecuária Brasileira, v.41, n.3, p.469-476, 2006.

BUMPUS, J.A.; AUST, S.D. Biodegradation of chlorinated organic compounds by Phanerochaete chrysosporium, a wood-rotting fungus. In: EXNER, J.H. (Ed.). Solvent 90 Hazardous waste problems: learning from dioxins. Washington DC: American lety, 1987. p.340-349.

BRO-RASMUSSEN, F. Contamination by persistent chemicals in food chain and human health. The Science of Total Environment, v.188, p.45-60, 1996.

CAMERON, M.D.; TIMOFEEVSKI, S.; AUST, S.D. Enzimology of Phanerochaete chrysosporium with respect to the degradation of recalcitrant compounds and xenobiotics. Applied Microbiology Biotechnology, v.54, p.751-758, 2000.

CHAKRADEO, P.P.; KAYAL, P.P.; BHIDE, S.V. Effect of benzo(a)pireno and methyl (acetoxymethyl) nitrosamine on thymidine uptake and induction of aryl hydrocarbon hydroxylase activity in human fetal esophageal cells in culture. Cellular Biology International, v.17, n.7, p. 671-676, 1993.

CHAILLAN, F.; LE FLECHE, A.; BURY, E.; PHANTAVONG, Y.; GRIMONT, P.; SALIOT, P.; SALIOT, A.; OUDOT, J. Identification and biodegradation potential of tropical aerobic hydrocarbon-degrading microorganisms. Research in Microbiology,v.155, n.7, p.587-595, 2004.

CHEW, I.; OBBARD, J.P.; STANFORTH, R.R. Microbial cellulose decomposition in soils from a rifle range contaminated with heavy metals. Environmental Pollution, v.111, p.367-375, 2001.

COLLA, L.M.; PRIMA, A.L.; LIMA, M.; BERTOLIN, T.E.; COSTA, A.V. Isolamento e seleção de fungos para biorremediação a partir de solo contaminado com herbicidas triazínicos. Ciência e Agrotecnologia, v.32, n.3, p.809-813, 2008.

CONCEIÇÃO, D.M.; ANGELIS, D.A.; BIDOIA, E.D.; ANGELIS, D. de F. Fungos filamentosos isolados do Rio Atibaia, SP e refinaria de petróleo biodegradadores de compostos fenólicos. Arquivo do Instituto Biologico, São Paulo, v.72, n.1, p.99-106, 2005.

COOLEY, R.N.; THURMAN, D.A.; TOMSETT, A.B. Molecular mechanisms of heavy-metal tolerance in Aspergillus nidulans. Heredity, v.57, p.133-134, 1986.

CORSEUIL, H.X.; AIRES, J.R.; ALVAREZ, P.J.J. Implications of the presence of ethanol on intrinsic 
bioremediation of BTEX plumes in Brazil. Hazardous Waste \& Hazardous Materials, v.13, n.2, p.213-221, 1996.

COSTA, C.N.; MEURER, E.J.; BISSANI, C.A.; SELBACH, P.A. Contaminantes e poluentes do solo. In: MEURER, E.J. (Ed.). Fundamentos de química do solo. 2.ed. Porto Alegre: Gênesis, 2004. p.207-237.

CRAPEZ, M. Efeitos dos hidrocarbonetos de petróleo na biota marinha. In: MORAES, R. et al. Efeito de poluentes em organismos marinhos. São Paulo: Arte e Ciência, 2001. p.253-267.

DEACON, J. W. Structure and ultrastructure: modern mycology. Cambridge, 1998. 35p.

EMBRAPA. Informação tecnológica. Recuperação de áreas degradadas com plantas inoculadas com micro-organismos. Disponível em: < http:/ / www.sct.embrapa.br/ diacampo/2002.htm >. Acesso em: 15 jan de 2006.

ESTEVES-NUNEZ, A.; CABALLERO, A.; RAMOS, J.L. Biological degradation of 2,4,6-trinittrotolvene. Microbiology and Molecular Biology Reviews, v.65, p.335-352, 2001.

ELLIS, M.B.; ELLIS, J.P. Microfungi on Land Plants. An Identification Handbook. England, 1997. 293p.

GAAD, G.M. Bioremedial potential of microbial mechanism of metal mobilization and immobilization. Current Opinion in Biotecnology, v.11, p.271-279, 2000.

GALVÃO, J.G.; GUERREIRO, M.C.; SOUZA, J.A.; COURA, S.M.C. Uso do fungo Fusarium oxysporum como indicador de Ametrina, através da medida de biomassa, pela quantificação do ergosterol. Ciências Agrotecnológicas, v.27, n.4, p.840-845, 2003.

GEERDINK, M.J.; LOOSDRECHT, M.C.M.; LUYBEN, K.C.A.M. Biodegradability of diesel oil. Biodegradation, v.7, p.73-81, 1996

GUILHERME, L.R.G.; LIMA, J.M.; ANDERSON, S.J. Efeito do fósforo na adsorção de cobre em horizontes A e B de Latossolos do Estado de Minas Gerais. In: CONGRESSO BRASILEIRO DE CIÊNCIA DO SOLO, 1995, Viçosa. Anais. Santa Maria, 1995. p.316-318.

GUGLIOTTA, A.M. Utilização de basidiomicetos nativos na remoção de corantes em efluentes da indústria têxtil. 2001. 115 p. Tese (Doutorado) - Universidade de São Paulo, São Paulo, 2001.

HAIDER, K. Microbe-soil-organic contaminant interactions. In: ADRIANO, D.C.; BOLLAG, J.M.; FRANKENBERGE JUNIOR, W.T.; SIMS, R.C. (Ed.). Bioremediation of contaminated soils. Madison: ASA/CSSA/SSSA, 1999. p.33-51.

HASELWANDTER, K.; BERRECK, M. Fungi as bioindicators of radiocesium contamination: pre and post chernobyl activities. Transctions of the Bristish Mycological Society, v.90, p.171-174, 1988.

HOFRICHTER, M.; GTINTHER, T. FRITSCHE, W. Metabolism of phenol, chloro- and nitrophenois by the penicillium strain $B i 7 / 2$ isolated from a contaminated soil. Biodegradation, v.3, p.415-421, 1993.

HOGGBLOM, M.M. Microbial breakdown of halogenated aromatic pesticides and related compounds. FEMS Microbiology Reviews, v.103, p.29-72, 1992.

HÖLKER, U.; FAKOUSSA, R.M.; HÖFER, M. Growth substrates control the ability of Fusarium oxysporum to solubilize low-rank coal. Applied Microbiology and Biotechnology, v.44, p.351-355, 1995.

JACQUES, R.J.S.; SANTOS, E.C.; BENTO, F.M.; PERALBA, M.C.R.; SELBACH, P.A.; SA, E. L. S.; CAMARGO, F. A. O. Anthracene biodegradation by Pseudomonas $\mathrm{sp}$ isolated from a petrochemical sludge landfarming. International Biodeterioration and Biodegradation, v.56, n.3, p.143-150, 2005.

JACQUES, R.J.S.; OKEKE, B.C.; BENTO, F.M.; PERALBA, M.C.R.; CAMARGO, F.A.O. Characterization of a polycyclic aromatic hydrocarbon-degrading microbial consortium from a petrochemical sludge landfarming site. Bioremediation Journal, v.11, n.1, p.1-11, 2007.

JACQUES, R.J.S.; SILVA, K.J. da; BENTO, F.M.; CAMARGO, F.A.O. Biorremediação de um solo contaminado com antraceno sob diferentes condições físicas e químicas. Ciência Rural, v.40, n.2, p.280-287, 2010. online.

SILVA JÚNIOR, F.M.R. da; PEREIRA, S.V. Ecologia e fisiologia de fungos filamentosos isolados de solo contaminado por metais pesados. Revista Brasileira de Biociências, v.5, n.2, p.903-905, 2007. Suplemento 2 (Nota Científica).

KAWAMOTO, K.; SHIM, S.S. Enzyme production activity of Phanerochaete chrysosporium and degradation of pentachlorophenol in a bioreactor. Water Research, v.36, p.4445-4454, 2002.

KHINDARIA, A.; GROVER, T.A.; AUST, S.D. Reductive dehalogenation of aliphatic halocarbons by lignin peroxidase of Phanerochaete chrysosporium. Environmental Science Technology, v.29, p.719-725, 1975.

KRISHNA. C. Solid-state fermentation systems - an overview. Critical Reviews in Biotechnology, v.25, p.1-30, 2005.

KUO, W.S.; REGAN, R.W. Degradation of carbaryl and 1-naphthol by spent mushroom compost microorganisms. Water Science Technology, v.26, n.9/11, p.2081-2084, 1992.

MACEDO, R.C.; BERBERT, V.H.C. Biorremediação de solos impactados por óleo cru utilizando fungos filamentosos. In: JORNADA DE INICIAÇÃO CIENTÍFICA, 
10., 2002, Rio de Janeiro. Anais. Rio de Janeiro: Centro de Tecnologia Mineral - CETEM, 2002.

MACHADO, K.M.G.; MATHEUS, D.R.; MONTEIRO, R.T.R.; BONONI, V.L.R. Biodegradation of pentachlorophenol by tropical basidiomycetes in soils contaminated with industrial residues. World Journal of Microbiology and Biotechnology, v.21, p.297-301, 2005.

MALAVOLTA, E. Fertilizantes e seu impacto ambiental, micronutrientes e metais pesados: mitos, mistificação e fatos. São Paulo: Produquímica, 1994. 153p.

MATHEUS, D.R.; BONONI, V.L.R.; MACHADO, K.M.G. Biodegradation of hexachlorobenzene by basidiomycetes in soil contaminated with industrial residues. World Journal of Microbiology and Biotechnology, v.16, n.5, p.415-421, 2000. Disponívem em: < http:/ / www.sct.embrapa.br/diacampo/2002.htm>.

MENDES FILHO, P.F.; VASCONCELLOS, R.L.F.; PAULA, A.M.; CARDOSO, E.J.B.N. Evaluating the potential of forest species under microbial management of the restoration of degraded mining areas. Water, Air and Soil Pollution, v.208, n.1/4, p.79-89, 2010.

MENDONÇA, M.M.; FLORES, A.C.; PIN, H.K.; BESSON, J.C.F.; SOARES, I.A. Avaliação da sobrevivência de Aspergillus nidulans em meios com metais pesados. In: SEMINÁRIO INTERNACIONAL DE CIÊNCIA, TECNOLOGIA E AMBIENTE, 1., 2009, Cascavel. Anais. Cascavel, 2009. v.1, p.1-9.

MONTIEL, A.M.; FERNÁNDEZ, F.J.; MARCIAL, J.; SORIANO, J.; BARRIOS-GONZÁLEZ, J.; TOMASINI. A. A fungal phenoloxidase (tyrosinase) involved in pentachlorophenol degradation. Biotechnology Letters, v.26, p.1353-1357, 2004

MORALES, I.C.; PAZOS, C.B. Pentaclorofenol: toxicología y riesgos para el ambiente. Madera y Bosques, v.4, p.21-37, 1998.

NIES, D.H. Microbial heavy-metal resistance. Applied Microbiology Biotechnolology, v.51. p.730-750, 1999.

NOBLES, M.K. Identification of cultures of wood-inhabiting Hymenomycetes. Canadian Journal of Botany, v.43, p.1097-1139, 1975.

OLIVEIRA, F.J.; FRANÇA, F.P. de Increase in removal of polycyclic aromatic hydrocarbons during bioremediation of crude oil-contaminated sandy soil. Applied Biochemistry and Biotechnology, v.121/124, p.593-603, 2005.

PAOLETTI, M.G. Using bioindicators based on biodiversity to assess landscape sustainability. Agriculture, Ecosystems E Environment, v.74, p.1-18, 1999.

PASSOS, C.T.; BURKERT, J.F.M.; KALIL, S.J.; BURKERT, C.A.V. Biodegradação de fenol por uma nova linhagem de Aspergillus sp. isolada de um solo contaminado do sul do Brasil. Química Nova, v.32, n.4, p.950-954, 2009.

PEINTNER, U.; MOSER, M. Survey of heavy metal deposition at the schulterberg (Achenkirch Altitude Profile) by using basidiomycetes as bioindicators. Phyton-Annales Rei Botanicae, v.35, n.4, p.155-162, 1996.

PERALTA-ZAMORA, P.; MORAES, S.G. de; ESPOSITO, E.; ANTUNES, R.; REYES, J.; DURÁN, N. Decolorization of Pulp Mill Effluents with Immobilized Lignin and Manganese Peroxidase from Phanerochaete Chrysosporium. Environmental Technology, v.19, n.5, p.521-528, 1998.

PIECKOVÁ, E.; JESENSKÁ, Z. Microscopic Fungi In Dwellings And Their Health Implications in humans. Annals of Agricultural and Environmental Medicine, p.6-11, 1999.

PIRES, F.R. Inferências sobre atividade rizosférica de espécies com potencial para fitorremediação do herbicida tebuthiuron. Revista Brasileira de Ciências do Solo, v.29, n.4, p.627-634, 2005.

POINTING, S.B. Feasibility of bioremediation by whiterot fungi. Applied Microbiology and Biotechnology, v.57, p.20-33, 2001.

REDDY, G.V.B.; GELPKE, M.D.S.; GOLD, M.H. Degradation of 2,4,6-trichlorophenol by Phanerochaete chrysosporium: Involvement of Reductive Dechlorination. Journal of Bacteriology, v.180, n.19, p.5159-5164, 1998.

REDDY, G.V.B.; GOLD, M.H. Degradation of pentachlorophenol by Phanerochaete chrysosporium: intermediates and reactions involved. Microbiology, v.146, p.405413, 2000.

RODRIGUES, K.A.; SAMPAIO, G.M.M.; ZAIAT, M.; SANTAELLA, S. T. Influência da glicose sobre o consumo de fenol por Aspergillus niger an 400 em reatores em batelada. Engenharia Sanitária Ambiental, v.12, n.2, p.222-228, 2007.

RODRIGUEZ, E.; NUERO, O.; GUILLÉN, F.; MARTÍNEZ, A.T.; MARTÍNEZ, M.J. Degradation of phenolic and non-phenolic aromatic pollutants by four Pleurotus species: the role of laccase an versatile peroxidase. Soil Biology e Biochemistry, v.36, p.909-916, 2004.

SANTOS, R.F.; MONTENEGRO, M.A.P.; LUZ, L.B.; CORSEUIL, H.X. Influência do etanol da biodegradação do benzeno em aquíferos contaminados com derramamentos de gasolina. In: SIMPÓSIO ÍTALOBRASILEIRO DE ENGENHARIA SANITÁRIA E AMBIENTAL (SIBESA), 3., 1996, Gramado. Anais. Gramado, 1996.

SICILIANO, S.D.; GERMIDA, J. J.; BANKS, K.; GREER, C. W. Changes in microbial communit composition and during a polyaromatic hidrocarbon phitoremediation 
field trial. Applied and Environmental Microbiology, v.69, n.1, p.483-489, 2003.

SILVA, R.F.; ANTONIOLLI, Z.I.; ANDREAZZA, R.; JUNIO, C.O.M. Seleção de fungos ectomicorrízicos tolerante a cobre em meio de cultura. 2007, Disponível em: <http://w3.ufsm.br/ppgcs/congressos/CBCS_RECIFE/BIOLOGIA.pdf>. Acesso em: 6 jun. 2008.

SINGH, HARBHAJAN. Mycoremediation: fungal bioremediation. New Jersey: John Wiley \& Sons, 2006. 592p.

SODRÉ, F.F.; LENZI, E. Utilização de modelos físicoquímicos de adsorção no estudo do comportamento do cobre em solos argilosos. Química Nova, v.24, n.3, p.324-330, 2001.

SPROCATI, A. Investigating heavy metals resistance, bioaccumulation and metabolic profile of a metallophile microbial consortium native to an abandonedmine. Science of the total Environment. v.366, p.649-658, 2006.

SUKUL, P.; SPITELLER, M. Sorption study of metalaxyl in soils of different physico-chemical properties. Fresenius Environmental Bulletin, v.9, p.701-710, 2000.

TIEN, M.; KIRK, T.K. Lignin-degrading enzyme from Phanerochaete chrysosporium: purification, characterization, and catalytic properties of a unique $\mathrm{H}_{2} \mathrm{O}_{2}$. Requiring Oxygenase, v.81, p.2280-2284, 1988.

TORTELLA, G.R.; DIEZ, M.C.; DURÁN, N. Fungal Diversity and Use in Decomposition of Environmental Pollutants. Critical Reviews in Microbiology, v.3, p.197212, 2005

TURPEINEN, R.; VIRTA, M.; HÄGGBLOM, M.M. Analysis of arsenic bioavailability in contaminated soils.
Environmental Toxicology and Chemistry, v.22, n.1, p.1-6, 2003.

ULLAH, M.A.; BEDFORD, C.T.; EVANS, C.S. Reactions of pentachlorophenol with laccase from Coriolus versicolor. Applied Microbiology Biotechnology, v.53, p.230-234, 2000.

VITALI, V.M.V.; MACHADO, K.M.G.; ANDREA, M.M.; BONONI, V.L.R. Screening mitosporic fungi for organochlorides degradation. Brazilian Journal of Microbiology, v.37, p.256-261, 2006.

WENZEL, J. B.; WENZEL, P.C.S.; LOPES-SHIKIDA, S.A.R.; SOARES, I.A. Isolamento e caracterização do fungo filamentoso isolado de peças anatômicas conservados em formol. 2006. Monografia. (Especialização em Microbiologia Aplicada) - Universidade Paranaense, Toledo, 2006.

WILSON, C.; TISDELL, C. Why farmers continue to use pesticides despite environmental, health and sustainability cost. Ecological Economics, v.39, p.449-462, 2001.

ZHDANOVA, N.N.; ZAKHARCHENKO, V.A.; VEMBER, V.V.; NAKONECHNAYA, L.T. Fungi from Chernobyl: mycobiota of the inner regions of the containment structures of the damaged nuclear reactor. Mycological Research, v.104, p.1421-1426, 2000.

ZOUARI, H.; LABAT, M.; SAYADI, S. Degradation of 4-chorophenol by the white rot fungus Phanerochaete chrysosporium in free and immobilized cultures. Bioresource Technology, v.84, p.145-150, 2002.

Recebido em 15/1/10

Aceito em 27/4/11 